\title{
Patterns and determinants of stress among consultant physicians working in Saudi Arabia
}

This article was published in the following Dove Press journal:

Advances in Medical Education and Practice

\author{
Fahad D Alosaimi' \\ Hossam S Alawad ${ }^{2}$ \\ Ayedh K Alamri ${ }^{2}$ \\ Abdullah I Saeed ${ }^{2}$ \\ Khalid A Aljuaydi ${ }^{2}$ \\ Alwaleed S Alotaibi ${ }^{2}$ \\ Khalid M Alotaibi ${ }^{2}$ \\ Eiad A Alfaris ${ }^{3}$
}

'Department of Psychiatry, College of Medicine, King Saud University, Riyadh, Kingdom of Saudi Arabia; ${ }^{2}$ Department of Psychiatry, College of Medicine, King Saud University, Riyadh, Kingdom of Saudi Arabia; ${ }^{3}$ King Saud University Chair for the Development of Medical Education, Department of Family and Community Medicine, College of Medicine, King Saud University, Riyadh, Kingdom of Saudi Arabia
Correspondence: Fahad D Alosaimi Psychiatry Department \# 55, King Khalid University Hospital, King Saud University, PO Box 7805, Riyadh I I472, Kingdom of Saudi Arabia

Tel +966 I| 467 |7|

Fax +966 I| 467257 ।

Email dr.fahad.alosaimi@gmail.com
Background: Physicians experience several work-related stressors that have been mounting up in recent decades. This study aimed to examine perceived stress and its risk factors and consequences among consultant physicians in Saudi Arabia.

Methods: A cross-sectional study was conducted from November 2014 to March 2015 among physicians who were assigned rank of consultant. The stress level was assessed using perceived stress scale (PSS).

Results: A total of 582 consultants participated. The average age was $46.9 \pm 7.9$ years, $71 \%$ were males, $56 \%$ were Saudi, $15 \%$ were smokers, and $68 \%$ slept $\leq 6$ hours per night. The median PSS score was 17 (interquartile range of 14-21), which represented 44\% of maximum possible PSS score. The upper tertile of PSS score (represents a high stress level) was significantly associated with being younger, female, and Saudi. The majority ( $85 \%$ ) considered job environment to be stressful and $\sim 50 \%$ attributed that to a high workload and a noncooperative administration. In the year preceding this study, half of consultants frequently contemplated or even worked toward changing their medical institutes or even moving to work outside Saudi Arabia because of perception of a stressful working environment. Over the previous year, encountering life stressors, considering job environment as stressful and experiencing passive suicidal ideation, were significantly associated with higher levels of stress. In multivariate analysis, the following factors were independently associated with stress: female gender (odds ratio $[\mathrm{OR}]=2.41,95 \%$ CI 1.58-3.70) and perceived stressful working environment (OR=3.66, 95\% CI 1.87-7.17).

Conclusion: Consultant physicians in Saudi Arabia experience moderate to high levels of perceived stress that are relatively comparable to physicians worldwide. A significant association was found between stress levels and both female gender and perception of a stressful working environment. Further studies are required to assess physician-based interventions and organization-directed approaches to management of stress among physicians.

Keywords: stress, Saudi Arabia, consultants, patterns, risk factors.

\section{Introduction}

Every day, physicians encounter stressors that are a fundamental part of medical practice. ${ }^{1}$ However, in the past few decades, compared with other professional groups, physician's wellness has diminished in every aspect of professional life. ${ }^{2}$ Chronic stress may affect the relationship of physicians with their patients and can lead to negative clinical consequences, such as compassion fatigue, unprofessionalism, and clinical errors. ${ }^{2-5}$ Chronic stress can also affect a physician's personal life and result in negative outcomes, such as chronic fatigue, substance abuse, psychiatric morbidity, and suicidal ideation. ${ }^{2-5}$ 
Physicians face several types of stressors that have worsened in recent decades. ${ }^{4}$ Work-related stressors include, but are not limited to, less autonomy because of the widespread adoption of evidence-based practice protocols and guidelines, ${ }^{6}$ working in larger groups, and being subjected to scrutiny regarding to their intervention and treatment plans. ${ }^{4}$ Moreover, physicians are concerned about increasing number of complaints, ${ }^{7}$ the costs of liability insurance, and the development of the judicialization of care. ${ }^{8}$

Most studies speculate on the possible causes of stress among physicians or on specific subgroups, and few have used standardized validated rating scales to measure stress. There are few international studies that have included consultant physicians from all specialties and that have provided considerable information about their current level of stress. ${ }^{9}$ Moreover, there are few local studies that have addressed stress among physicians. One old local study has addressed stress among physicians in a single academic hospital, ${ }^{10}$ and another study investigated burnout phenomena in a tertiary care hospital. ${ }^{11}$ Therefore, the objective of the present study was to examine perceived stress and its associated risk factors and consequences among consultant physicians in Saudi Arabia.

\section{Methods}

\section{Population}

All consultant physicians who registered with the Saudi Commission for Health Specialties (SCFHS) registry were invited to participate in the study. According to the SCFHS, which is the body responsible for setting regulations for the practice of health professions in Saudi Arabia, the consultant physician must possess a Saudi specialty certificate (or equivalent) and have at least 3 years of experience in a specialty field at a recognized hospital or center. ${ }^{12}$ Both Saudi and non-Saudi consultants from all medical specialties working in both public and private sectors of the five Saudi regions (central, northern, southern, eastern, and western) were qualified for inclusion in the study. The SCFHS maintains a comprehensive record of all health care practitioners in Saudi Arabia.

\section{Study design}

This was a cross-sectional study. Ethical approval was obtained from the Ethical Institutional Review Board at King Saud University, College of Medicine, Riyadh, Saudi Arabia. We got approval for use of the third party data from the SCFHS registry. Written informed consent was obtained from participants.

\section{Recruitment}

Due to lack of previous local studies that identified the frequency of stress among consultants, estimation of the sample size was based on the assumption of $50 \%$ frequency of stress among consultants, which is known to be associated with the most liberal estimation of sample size. Therefore, the required sample size was estimated to be 376 consultants, using $95 \%$ CI. All consultants who were listed in the SCFHS registry between November 2014 and March 2015 and who had available cell numbers $(n=11621)$ were invited to participate via cell phone text messages. Up to three reminder messages were sent to nonresponders. The messages explained the study objectives and directed the physician to a website to complete the study questionnaire. The first page of the website was an informed consent form, which offered the prospective participant two options: to withdraw with a provided reason or to proceed to the study questionnaire.

Overall, 623 consultants initiated the internet-based questionnaire. Subsequently, 41 consultants were excluded; 31 consultants did not consent (the majority stated that the main reason was lack of time), and 10 were found to be specialists (not yet consultants, as they did not complete the required 3 years of specialty training/experience). Therefore, 582 consultants were eventually included in the current analysis.

\section{Data collection tool}

A self-administered internet-based questionnaire was developed that included demographic characteristics, personal clinical history, job-related characteristics, work-related and other stressors, ideations, and stress management questions.

\section{Instrument}

The perceived stress scale (PSS) is a 10-question tool used to measure a person's perception of stress over the past month. ${ }^{13,14}$ The PSS is a validated, easy-to-use, and popular stress questionnaire with established acceptable psychometric properties. $^{15,16}$

A Likert-type scale was used to capture responses in the PSS (never, almost never, sometimes, fairly often, or very often). Consultants were asked about their feelings and thoughts during the last month. Respondents were requested to circle how often they felt or thought a certain way $(0=$ never, $1=$ almost never, $2=$ =sometimes, $3=$ fairly often, and $4=$ very often). The total PSS score was calculated by summing the scores of individual questions, with higher scores equal to higher levels of stress. However, PSS scores are obtained by reverse-scoring the responses (eg, $0=4,1=3,2=2,3=1$, and 
$4=0$ ) to the four positively stated items (items 4,5 , 7, and 8).

The total sum score of PSS can range from 0 to 40 .

\section{Validation of the data collection tool}

The content of the questionnaire (apart from the PSS) was validated by a multidisciplinary committee that included specialists in psychiatry, family medicine, medical ethics, and epidemiology. The questionnaire was piloted with 20 consultants. After 2 weeks, the questionnaire was then readministered to the same consultants with more than $90 \%$ test-retest reliability. The tool demonstrated consistency in its internal items as indicated by an overall Cronbach's alpha of 0.844 .

\section{Statistical analysis}

The PSS scores and demographic data were entered in the SPSS (version 22.0; IBM Corp, Armonk, NY, USA). Data were presented as frequencies and percentages for categorical data, mean and SD for continuous normally distributed data, and median and interquartile range (IQR) for continuous non-normally distributed data. Chi-square tests or Fisher's exact tests (as appropriate) were used to compare categorical data, whereas analysis of variances or Kruskal-Wallis tests (as appropriate) were used to compare continuous data. Spearman's correlation $(r)$ was used to examine the correlation between the PSS and other continuous variables. A $P$-value of $<0.05$ was considered significant. As there is no standard cut-score to diagnose and/or grade stress, ${ }^{14}$ the score of the PSS was categorized into three roughly equal categories (tertiles): low score (PSS $\leq 15)$, intermediate score ( $\mathrm{PSS}=16-19)$, and high score ( $\mathrm{PSS} \geq 20$ ). Multivariate logistic regression model was run to detect independent associations between PSS (highest tertile versus the other two tertiles) and potential predictor variables (such as demographic, clinical, and job characteristics). Factors that were significantly/marginally associated with perceived stress groups in univariate analysis $(P<0.10$, as shown in Tables $1-3)$ were entered into the multivariate model, whereas nonsignificant variables were allowed to exit the model by the backward elimination method. Variables that remained in the final step with $P$-value of $<0.05$ was considered independently associated with perceived stress.

\section{Results}

A total 582 participated consultants were included in the current analysis. The median and IQR of PSS score was 17 (14-21) while the mean \pm SD was $17.7 \pm 5.4$. The average PSS score represented $44 \%$ of the maximum possible score of the test. Approximately $33.8 \%$ of the consultants had a PSS score $\geq 20$ (upper tertile).

Table 1 shows the sociodemographic and clinical characteristics of the participated consultants. They had an average age of $46.9 \pm 7.9$ years. They were typically married (93\%), males (71\%), and Saudi (56\%). The majority (91\%) of the consultants had children, with $77 \%$ of them had three or more children. Most (68\%) of the consultants slept $\leq 6$ hours per day and $15 \%$ were smokers. Up to $15 \%$ of the consultants had one or more chronic medical illness, with hypertension (6\%), diabetes (5\%), and heart disease (2\%) among the most common. Only $5 \%$ of the consultants had a personal history of psychiatric disorders that included depression (3.8\%) and anxiety (1.4\%), whereas $7 \%$ of the consultants had received professional psychological help. When the sociodemographic and clinical characteristics were compared between stress groups, the upper tertile of the PSS score (which represented a high stress level) was significantly associated with younger age $(P=0.001)$, female gender $(P<0.001)$, and Saudi nationality $(P<0.001)$. Additionally, significant correlations were detected between PSS score and age $(r=-0.168, P<0.001)$ as well as daily sleeping hours ( $r=-0.117, P=0.005)$.

Table 2 shows work-related characteristics among the participated consultants. Most of the consultants were working in public hospitals, either alone $(75 \%)$ or with private hospitals (8\%). The consultants were distributed into at least 14 specialties, with the most common being internal medicine, surgery, pediatrics/neonatology, obstetrics and gynecology, family medicine, anesthesiology, psychiatry, radiology, and laboratory. The average number (median and IQR) of the oncalls was 7 (4-10) on-calls per month and the average number (median and IQR) of the served ward patients was 10 (4-20) patient per week. The majority (61\%) had an income of at least SR 40,000 ( \$10,667) per month, with 54\% who were satisfied with their income and 34\% who were dissatisfied with their income. No significant correlations were detected between PSS score and the number of on-calls per month ( $r=-0.004, P=0.582$ ) or the number of served ward patients for per week ( $r=-0.056, P=0.177)$. Additionally, none of the other work-related characteristics was significantly associated with the level of stress.

The responses to the 10 items of PSS that comprise the consultants' feelings over the month preceding the survey were variable. Regarding negative feelings, $39 \%$ of the consultants (fairly or very) often felt nervous and stressed. Similarly, $35 \%$ of the consultants often felt upset because of unexpected occurrences, whereas $28 \%$ often felt angered because of things that were outside of their control. For 
Table I Demographic characteristics and medical history by stress level among consultant physicians in Saudi Arabia ( $\mathrm{n}=582$ )

\begin{tabular}{|c|c|c|c|c|c|}
\hline Characteristics & Total & $\begin{array}{l}\text { Low } \\
\text { (PSS } \leq 15)\end{array}$ & $\begin{array}{l}\text { Medium } \\
(\text { PSS }=16-19)\end{array}$ & $\begin{array}{l}\text { High } \\
\text { (PSS } \geq 20)\end{array}$ & $P$-value \\
\hline Overall & $582(100.0 \%)$ & $197(33.8 \%)$ & $188(32.3 \%)$ & 197 (33.8\%) & \\
\hline \multicolumn{6}{|l|}{ Gender } \\
\hline Male & $4 \mid 4$ (7I.1\%) & 159 (38.4\%) & $139(33.6 \%)$ & $116(28.0 \%)$ & $<0.001$ \\
\hline Female & $168(28.9 \%)$ & $38(22.6 \%)$ & 49 (29.2\%) & 81 (48.2\%) & \\
\hline Age (years) & $46.9 \pm 7.9$ & $48.3 \pm 7.6$ & $47.1 \pm 8.1$ & $45.4 \pm 7.8$ & 0.001 \\
\hline \multicolumn{6}{|l|}{ Nationality } \\
\hline Saudi & $326(56.0 \%)$ & 91 (27.9\%) & $104(31.9 \%)$ & $|3|(40.2 \%)$ & $<0.001$ \\
\hline Non-Saudi & $256(44.0 \%)$ & $106(41.4 \%)$ & $84(32.8 \%)$ & $66(25.8 \%)$ & \\
\hline \multicolumn{6}{|l|}{ Marital status } \\
\hline Single & $23(4.0 \%)$ & $5(21.7 \%)$ & II (47.8\%) & 7 (30.4\%) & 0.191 \\
\hline Married & $540(92.8 \%)$ & $188(34.8 \%)$ & $166(30.7 \%)$ & $186(34.4 \%)$ & \\
\hline Other & $19(3.3 \%)$ & $4(21.1 \%)$ & II (57.9\%) & $4(21.1 \%)$ & \\
\hline \multicolumn{6}{|l|}{ Children } \\
\hline No & $50(8.6 \%)$ & $14(28.0 \%)$ & $15(30.0 \%)$ & $21(42.0 \%)$ & 0.424 \\
\hline Yes & $532(91.4 \%)$ & $183(34.4 \%)$ & $173(32.5 \%)$ & $176(33.1 \%)$ & \\
\hline \multicolumn{6}{|l|}{ Number of children } \\
\hline $\mathrm{I}-2$ & $123(23.2 \%)$ & $50(40.7 \%)$ & $33(26.8 \%)$ & $40(32.5 \%)$ & 0.051 \\
\hline $3-4$ & 264 (49.8\%) & 92 (34.8\%) & 79 (29.9\%) & 93 (35.2\%) & \\
\hline$\geq 5$ & 143 (27.0\%) & $4 \mathrm{I}(28.7 \%)$ & $60(42.0 \%)$ & $42(29.4 \%)$ & \\
\hline \multicolumn{6}{|l|}{ Smoking } \\
\hline No & 494 (84.9\%) & $170(34.4 \%)$ & $163(33.0 \%)$ & $16 \mid(32.6 \%)$ & 0.313 \\
\hline Yes & $88(15.1 \%)$ & 27 (30.7\%) & $25(28.4 \%)$ & $36(40.9 \%)$ & \\
\hline Sleeping hours per day & $6.0 \pm 1.0$ & $6.1 \pm 1.0$ & $5.9 \pm I . I$ & $5.9 \pm 1.0$ & 0.060 \\
\hline \multicolumn{6}{|l|}{ Chronic medical illness } \\
\hline No & $492(84.5 \%)$ & $170(34.6 \%)$ & 159 (32.3\%) & $163(33.1 \%)$ & 0.621 \\
\hline Yes & $90(15.5 \%)$ & $27(30.0 \%)$ & $29(32.2 \%)$ & $34(37.8 \%)$ & \\
\hline \multicolumn{6}{|l|}{ Chronic medical illness } \\
\hline Hypertension & $36(6.2 \%)$ & $12(33.3 \%)$ & $8(22.2 \%)$ & 16 (44.4\%) & 0.289 \\
\hline Diabetes & $29(5.0 \%)$ & $8(27.6 \%)$ & 14 (48.3\%) & 7 (24.1\%) & 0.164 \\
\hline Heart disease & $13(2.2 \%)$ & $2(15.4 \%)$ & 7 (53.8\%) & $4(30.8 \%)$ & 0.194 \\
\hline Vertebral disc disease & $9(1.5 \%)$ & $2(22.2 \%)$ & $3(33.3 \%)$ & $4(44.4 \%)$ & 0.778 \\
\hline Thyroid & $5(0.9 \%)$ & $0(0.0 \%)$ & I (20.0\%) & $4(80.0 \%)$ & 0.090 \\
\hline Other & $23(4.0 \%)$ & $5(21.7 \%)$ & $10(43.5 \%)$ & $8(34.8 \%)$ & 0.347 \\
\hline \multicolumn{6}{|l|}{ Psychiatric illness } \\
\hline No & 549 (94.7\%) & 191 (34.8\%) & 177 (32.2\%) & I8I (33.0\%) & 0.127 \\
\hline Yes & $31(5.3 \%)$ & $6(19.4 \%)$ & $10(32.3 \%)$ & 15 (48.4\%) & \\
\hline \multicolumn{6}{|l|}{ Psychiatric illness } \\
\hline Depression & $22(3.8 \%)$ & 5 (22.7\%) & $6(27.3 \%)$ & II (50.0\%) & 0.246 \\
\hline Anxiety & $8(1.4 \%)$ & $0(0.0 \%)$ & $4(50.0 \%)$ & $4(50.0 \%)$ & 0.117 \\
\hline Other & $2(0.3 \%)$ & I (50.0\%) & I (50.0\%) & $0(0.0 \%)$ & 0.770 \\
\hline \multicolumn{6}{|c|}{ Received psychological help } \\
\hline No & $537(92.3 \%)$ & $186(34.6 \%)$ & $175(32.6 \%)$ & $176(32.8 \%)$ & 0.148 \\
\hline Yes & 45 (7.7\%) & II (24.4\%) & $13(28.9 \%)$ & 21 (46.7\%) & \\
\hline
\end{tabular}

Note: Data shown as mean \pm standard deviation and number (percentage).

Abbreviation: PSS, perceived stress scale.

positive feelings, $73 \%$ of the consultants often felt confident regarding their ability to handle their personal problems, whereas $61 \%$ often felt that they were able to control irritations in their life. Similarly, $49 \%$ of the consultants often felt that they were on top of things and $46 \%$ felt that things were going their way.

Table 3 shows stressors and ideations among participated consultants. Almost all (98\%) consultants reported facing one or more life stressors over the past year. The most common were work-related (69\%), family (41\%), financial (25\%), marital (19\%), health (19\%), and academic (17\%) stressors. The majority (85\%) considered their job environment to be stressful. The most commonly reported causes were workload (50\%), noncooperation from the administration (44\%), working long hours (30\%), low salary $(22 \%)$, and nonclinical loads such as research and teaching 
Table 2 Job characteristics by stress level among consultant physicians in Saudi Arabia $(n=582)$

\begin{tabular}{|c|c|c|c|c|c|}
\hline Characteristics & Total & $\begin{array}{l}\text { Low } \\
\text { (PSS } \leq 15)\end{array}$ & $\begin{array}{l}\text { Medium } \\
(P S S=16-19)\end{array}$ & $\begin{array}{l}\text { High } \\
(\text { PSS } \geq 20)\end{array}$ & $P$-value \\
\hline \multicolumn{6}{|l|}{ Type of health facility } \\
\hline Public & 438 (75.3\%) & $136(3 \mid .1 \%)$ & $153(34.9 \%)$ & 149 (34.0\%) & \multirow[t]{3}{*}{0.075} \\
\hline Private & $97(16.7 \%)$ & $43(44.3 \%)$ & $22(22.7 \%)$ & $32(33.0 \%)$ & \\
\hline Both & $47(8.1 \%)$ & $18(38.3 \%)$ & $13(27.7 \%)$ & $16(34.0 \%)$ & \\
\hline \multicolumn{6}{|l|}{ Job title } \\
\hline Associate consultant & 15 (2.6\%) & $5(33.3 \%)$ & 7 (46.7\%) & $3(20.0 \%)$ & \multirow[t]{3}{*}{0.493} \\
\hline Consultant & $519(89.2 \%)$ & $176(33.9 \%)$ & $169(32.6 \%)$ & $174(33.5 \%)$ & \\
\hline Senior consultant & $48(8.2 \%)$ & $16(33.3 \%)$ & $12(25.0 \%)$ & $20(41.7 \%)$ & \\
\hline \multicolumn{6}{|l|}{ Specialty } \\
\hline Internal medicine & 147 (25.3\%) & $43(29.3 \%)$ & $50(34.0 \%)$ & $54(36.7 \%)$ & \multirow[t]{10}{*}{-} \\
\hline Surgery & 138 (23.7\%) & 54 (39.1\%) & 46 (33.3\%) & $38(27.5 \%)$ & \\
\hline Pediatrics/neonatology & $86(14.8 \%)$ & $28(32.6 \%)$ & 27 (3I.4\%) & $31(36.0 \%)$ & \\
\hline Obstetrics and gynecology & $60(10.3 \%)$ & $15(25.0 \%)$ & $18(30.0 \%)$ & 27 (45.0\%) & \\
\hline Family medicine & 47 (8.1\%) & 15 (31.9\%) & $13(27.7 \%)$ & 19 (40.4\%) & \\
\hline Anesthesiology & 35 (6.0\%) & $19(54.3 \%)$ & $6(17.1 \%)$ & $10(28.6 \%)$ & \\
\hline Psychiatry & $23(4.0 \%)$ & $10(43.5 \%)$ & $8(34.8 \%)$ & $5(21.7 \%)$ & \\
\hline Radiology & $20(3.4 \%)$ & $2(10.0 \%)$ & $9(45.0 \%)$ & $9(45.0 \%)$ & \\
\hline Laboratory & 19 (3.3\%) & 9 (47.4\%) & 7 (36.8\%) & $3(15.8 \%)$ & \\
\hline Other & $7(1.2 \%)$ & $2(28.6 \%)$ & $4(57.1 \%)$ & I (14.3\%) & \\
\hline \multicolumn{6}{|l|}{ Work load } \\
\hline No. of on calls per month & $7(4-10)$ & $7(3-10)$ & $7(4-10)$ & $6(3-12)$ & 0.974 \\
\hline No. of served ward patients & $10(4-20)$ & $8(4-17)$ & $10(4-20)$ & $10(4-20)$ & 0.417 \\
\hline \multicolumn{6}{|l|}{ per week } \\
\hline \multicolumn{6}{|l|}{ Monthly income (SR) } \\
\hline$<40,000$ & $228(39.2 \%)$ & $72(31.6 \%)$ & 89 (39.0\%) & $67(29.4 \%)$ & \multirow[t]{3}{*}{0.082} \\
\hline $40,000-60,000$ & $248(42.6 \%)$ & $86(34.7 \%)$ & $69(27.8 \%)$ & $93(37.5 \%)$ & \\
\hline$>60,000$ & $106(18.2 \%)$ & 39 (36.8\%) & $30(28.3 \%)$ & 37 (34.9\%) & \\
\hline \multicolumn{6}{|l|}{ Income satisfaction } \\
\hline Satisfied & $316(54.3 \%)$ & $116(36.7 \%)$ & 95 (30.1\%) & 105 (33.2\%) & \multirow[t]{3}{*}{0.267} \\
\hline Dissatisfied & $199(34.2 \%)$ & $58(29.1 \%)$ & $67(33.7 \%)$ & $74(37.2 \%)$ & \\
\hline Not sure & $67(11.5 \%)$ & $23(34.3 \%)$ & $26(38.8 \%)$ & $18(26.9 \%)$ & \\
\hline
\end{tabular}

Note: Data shown as median (interquartile range) and number (percentage).

Abbreviation: PSS, perceived stress scale.

(19\%). The most frequently reported thoughts and actions related to work-related stress were changing hospital/ medical institute (53\% and 38\%, respectively), working outside Saudi Arabia ( $42 \%$ and 15\%, respectively), and moving to administrative/nonclinical work (11\% and $10 \%$, respectively). Approximately $5.8 \%$ had passive suicidal ideations and $0.7 \%$ had active suicidal ideation over the last year. Only $21 \%$ of participants were educated or trained in stress management. Facing one or more life stressors over the last year, considering the job environment to be stressful, or having passive suicidal ideations over the previous year were significantly associated with a higher level of stress $(P<0.001$ for all).

As shown in Table 4, when risk factors were significantly (even marginally) associated with perceived stress in the univariate analysis (including age, gender, nationality, number of children, hours of sleep, type of work facility, monthly income, and the perception of a stressful work environment) were entered into multivariate logistic regression analysis, the following factors remained in the model and were independently associated with (the highest tertile of) perceived stress: female gender (odds ratio [OR] $=2.41,95 \%$ CI $1.58-3.70$ ) and the perception of a stressful work environment $(\mathrm{OR}=3.66$, $95 \%$ CI 1.87-7.17). Presence of life stressors was removed from the model due to strong collinearity with stressful working environment. Having passive suicidal ideation in the past year was not entered in the model, as it was probably an outcome rather than a risk factor.

\section{Discussion}

To the best of our knowledge, this is the first nationwide study in Saudi Arabia that explored the rate of stress and its risk factors and consequences among consultant physicians across all specialties. The median PSS score in our study was 
Table 3 Stressors, ideations, and stress management training among consultant physicians in Saudi Arabia ( $n=582)$

\begin{tabular}{|c|c|c|c|c|c|}
\hline Characteristics & Total & $\begin{array}{l}\text { Low } \\
\text { (PSS } \leq 15)\end{array}$ & $\begin{array}{l}\text { Medium } \\
\text { (PSS=16-19) }\end{array}$ & $\begin{array}{l}\text { High } \\
\text { (PSS } \geq 20)\end{array}$ & $P$-value \\
\hline \multicolumn{6}{|l|}{ Faced any life stressor in the last year? } \\
\hline No & $13(2.2 \%)$ & II (84.6\%) & $2(15.4 \%)$ & $0(0.0 \%)$ & $<0.001$ \\
\hline Yes & $569(97.8 \%)$ & $186(32.7 \%)$ & $186(32.7 \%)$ & $197(34.6 \%)$ & \\
\hline \multicolumn{6}{|l|}{ Types } \\
\hline Work-related & 399 (68.6\%) & $119(29.8 \%)$ & $125(3 \mid .3 \%)$ & $155(38.8 \%)$ & $<0.001$ \\
\hline Family & 237 (40.7\%) & $67(28.3 \%)$ & $80(33.8 \%)$ & $90(38.0 \%)$ & 0.051 \\
\hline Financial & 144 (24.7\%) & $32(22.2 \%)$ & $50(34.7 \%)$ & $62(43.1 \%)$ & 0.002 \\
\hline Marital & $111(19.1 \%)$ & 22 (19.8\%) & 35 (31.5\%) & $54(48.6 \%)$ & $<0.001$ \\
\hline Health & $108(18.6 \%)$ & $24(22.2 \%)$ & $29(26.9 \%)$ & $55(50.9 \%)$ & $<0.001$ \\
\hline Academic & $101(17.4 \%)$ & $26(25.7 \%)$ & $34(33.7 \%)$ & $4 \mathrm{I}(40.6 \%)$ & 0.130 \\
\hline Death of a loved one & $74(12.7 \%)$ & $29(39.2 \%)$ & $19(25.7 \%)$ & $26(35.1 \%)$ & 0.385 \\
\hline Homesickness & $48(8.2 \%)$ & $13(27.1 \%)$ & 17 (35.4\%) & $18(37.5 \%)$ & 0.586 \\
\hline Other & $23(4.0 \%)$ & $9(39.1 \%)$ & $9(39.1 \%)$ & $5(21.7 \%)$ & 0.454 \\
\hline \multicolumn{6}{|l|}{ Is your current work environment stressful? } \\
\hline Agree & $492(84.5 \%)$ & 147 (29.9\%) & $159(32.3 \%)$ & $186(37.8 \%)$ & $<0.001$ \\
\hline Disagree & $47(8.1 \%)$ & $28(59.6 \%)$ & $13(27.7 \%)$ & $6(12.8 \%)$ & \\
\hline Not sure & $43(7.4 \%)$ & $22(51.2 \%)$ & $16(37.2 \%)$ & $5(11.6 \%)$ & \\
\hline \multicolumn{6}{|l|}{ Reasons } \\
\hline Workload (number or type of patients) & $292(50.2 \%)$ & $89(30.5 \%)$ & 91 (31.2\%) & $112(38.4 \%)$ & 0.057 \\
\hline Noncooperative administration & $257(44.2 \%)$ & $59(23.0 \%)$ & $85(33.1 \%)$ & $113(44.0 \%)$ & $<0.001$ \\
\hline Long working hours & $172(29.6 \%)$ & $55(32.0 \%)$ & $52(30.2 \%)$ & $65(37.8 \%)$ & 0.428 \\
\hline Low salary & $128(22.0 \%)$ & $40(31.3 \%)$ & $43(33.6 \%)$ & $45(35.2 \%)$ & $0.78 \mathrm{I}$ \\
\hline Nonclinical load (research or teaching) & $111(19.1 \%)$ & $32(28.8 \%)$ & $34(30.6 \%)$ & $45(40.5 \%)$ & 0.228 \\
\hline Conflict with colleagues & $102(17.5 \%)$ & $22(21.6 \%)$ & $38(37.3 \%)$ & $42(41.2 \%)$ & 0.015 \\
\hline Conflict with boss & $88(15.1 \%)$ & $21(23.9 \%)$ & 29 (33.0\%) & $38(43.2 \%)$ & 0.057 \\
\hline None of the above & $39(6.7 \%)$ & 27 (69.2\%) & $9(23.1 \%)$ & $3(7.7 \%)$ & $<0.001$ \\
\hline Other & 71 (12.2\%) & $26(36.6 \%)$ & $23(32.4 \%)$ & $22(31.0 \%)$ & 0.827 \\
\hline \multicolumn{6}{|l|}{ Thoughts } \\
\hline Changing hospital/medical institute & $310(53.3 \%)$ & $86(27.7 \%)$ & $104(33.5 \%)$ & $120(38.7 \%)$ & 0.002 \\
\hline Working outside Saudi Arabia & $243(41.8 \%)$ & $63(25.9 \%)$ & $81(33.3 \%)$ & $99(40.7 \%)$ & 0.001 \\
\hline Moving to administrative/nonclinical work & $61(10.5 \%)$ & $12(19.7 \%)$ & $20(32.8 \%)$ & $29(47.5 \%)$ & 0.020 \\
\hline Leaving medicine altogether & $96(16.5 \%)$ & $18(18.8 \%)$ & $29(30.2 \%)$ & $49(51.0 \%)$ & $<0.001$ \\
\hline Moving to a nonacademic institute & $28(4.8 \%)$ & $8(28.6 \%)$ & $7(25.0 \%)$ & $13(46.4 \%)$ & 0.349 \\
\hline None of the above & $|2|(20.8 \%)$ & $67(55.4 \%)$ & $35(28.9 \%)$ & $19(15.7 \%)$ & $<0.001$ \\
\hline Other & $35(6.0 \%)$ & $12(34.3 \%)$ & II (31.4\%) & $12(34.3 \%)$ & 0.994 \\
\hline \multicolumn{6}{|l|}{ Actions } \\
\hline Changing hospital/medical institute & $222(38.1 \%)$ & $56(25.2 \%)$ & $80(36.0 \%)$ & $86(38.7 \%)$ & 0.003 \\
\hline Working outside Saudi Arabia & $87(14.9 \%)$ & $27(31.0 \%)$ & $21(24.1 \%)$ & 39 (44.8\%) & 0.050 \\
\hline Moving to administrative/nonclinical work & $58(10.0 \%)$ & $10(17.2 \%)$ & $22(37.9 \%)$ & $26(44.8 \%)$ & 0.017 \\
\hline Leaving medicine altogether & $31(5.3 \%)$ & $10(32.3 \%)$ & $8(25.8 \%)$ & $13(4 \mid .9 \%)$ & $0.58 \mathrm{I}$ \\
\hline Moving to a nonacademic institute & $13(2.2 \%)$ & $2(15.4 \%)$ & $3(23.1 \%)$ & $8(61.5 \%)$ & 0.140 \\
\hline None of the above & $254(43.6 \%)$ & III (43.7\%) & $78(30.7 \%)$ & $65(25.6 \%)$ & $<0.001$ \\
\hline Other & $30(5.2 \%)$ & $7(23.3 \%)$ & $12(40.0 \%)$ & II (36.7\%) & 0.430 \\
\hline \multicolumn{6}{|l|}{$\begin{array}{l}\text { Had wishes of dying in the last year (passive } \\
\text { suicidal ideation) }\end{array}$} \\
\hline No or rarely & $548(94.2 \%)$ & $195(35.6 \%)$ & $177(32.3 \%)$ & $176(32.1 \%)$ & $<0.001$ \\
\hline Yes & $34(5.8 \%)$ & $2(5.9 \%)$ & II (32.4\%) & $21(61.8 \%)$ & \\
\hline \multirow{2}{*}{\multicolumn{6}{|c|}{$\begin{array}{l}\text { Had thoughts of ending your life in the last } \\
\text { year (active suicidal ideation) }\end{array}$}} \\
\hline & & & & & \\
\hline No or rarely & $578(99.3 \%)$ & $197(34.1 \%)$ & $185(32.0 \%)$ & $196(33.9 \%)$ & 0.127 \\
\hline Yes & $4(0.7 \%)$ & $0(0.0 \%)$ & $3(75.0 \%)$ & I $(25.0 \%)$ & \\
\hline \multicolumn{6}{|l|}{ Educated or trained in stress management } \\
\hline No & $46 \mid(79.2 \%)$ & $154(33.4 \%)$ & $148(32.1 \%)$ & $159(34.5 \%)$ & 0.808 \\
\hline Yes & $12 \mid(20.8 \%)$ & $43(35.5 \%)$ & $40(33.1 \%)$ & $38(31.4 \%)$ & \\
\hline
\end{tabular}

Note: Data shown as number (percentage). Abbreviation: PSS, perceived stress scale. 
Table 4 Multivariate logistic regression for potentially predictive factors* of higher perceptions of stress among consultant physicians in Saudi Arabia $(n=528)$

\begin{tabular}{|c|c|c|c|c|}
\hline \multirow[t]{2}{*}{ Variables } & \multirow{2}{*}{$\begin{array}{l}\text { Odds } \\
\text { ratio }\end{array}$} & \multicolumn{2}{|l|}{$95 \% \mathrm{Cl}$} & \multirow[t]{2}{*}{ P-value } \\
\hline & & Lower & Upper & \\
\hline Gender: female vs. male & 2.41 & 1.58 & 3.70 & $<0.001$ \\
\hline $\begin{array}{l}\text { Perceived stressful working } \\
\text { environment: yes vs. no }\end{array}$ & 3.66 & 1.87 & 7.17 & $<0.001$ \\
\hline
\end{tabular}

Notes: *Variables entered in the model included age, gender, nationality, number of children, hours of sleep, type of work facility, monthly income, and stressful working environment. As shown above, female gender and the perception of a stressful work environment were the only two variables to remain in the model after backward elimination.

17 (IQR 14-21), which means that our consultants experienced a stress level that is $44 \%$ of the highest possible stress level that can be detected by the tool. This moderate to high level of stress among our consultant physicians is relatively comparable to what has been reported worldwide. There are numerous studies from various parts of the world that have evaluated the presence of stress or risk factors for stress among physicians. ${ }^{2,6,9,17-31}$ However, we struggled to compare the findings from these studies because they used different tools to assess the presence of stress, study populations were varied, and validated stress scales to evaluate the presence of stress were used in only a few. For example, the average PSS was 15.5 among Emergency Physicians in Jamaica. ${ }^{32}$ The 2003 Canadian Community Health Survey that included 75,184 subjects, indicated that health care providers are far more likely than employed people in general to feel that their jobs are highly stressful; however, physicians and nurses reported the most stress, even when influences outside of the health care setting were taken into consideration. ${ }^{33}$ In England, $47 \%$ of consultant physicians scored positively on a different stress scale (the 28 -item general health questionnaire) compared with $27 \%$ in the general population. ${ }^{9}$ Among Dutch medical specialists, 55\% reported experiencing high or very high levels of stress. ${ }^{31}$

A literature search in the PubMed and Google Scholar databases did not find any studies that used the PSS to study stress among consultant physicians in Saudi Arabia. An old local study of one academic hospital in Riyadh found that $21 \%$ of the recruited physicians were "stressed to the limit" and $1.8 \%$ were stressed to a level of distress or impairment. ${ }^{10}$ Perceived stress measured by PSS among health care professionals has negative correlation with mindfulness, emotional intelligence, and subjective well-being scales but positive correlation with burnout scales. ${ }^{34,35}$ We used the PSS tool to detect the perceived stress among our consultants because it is a validated, short, easy-to-use, and popular stress questionnaire with established acceptable psychometric properties. ${ }^{15,16}$ Additionally, it has been validated in different populations including Arabs. ${ }^{36}$ Furthermore, it has been used locally to study stress among different levels of health professional such as medical residents, ${ }^{37}$ medical students, ${ }^{38}$ and dental students..$^{39}$ Interestingly, the local studies that used the same tool reported a higher mean PSS score than that of consultants in the current study. For example, the PSS score was 22 among medical residents, ${ }^{37} 21$ among medical students, ${ }^{38}$ and 23 among dental students. ${ }^{39}$ Other local studies that used the Kessler-10 psychological distress inventory found a high prevalence of stress among junior doctors during their internship training (73.0\%) ${ }^{40}$ during medical residency $(70.4 \%),{ }^{41}$ and during the medical school $(63 \%) .{ }^{42}$ Although there are no known normative data regarding the use of the PSS in Saudi Arabia, stress among consultants is probably higher than that of the general population. For instance, the normative data of the PSS based on a representative community US sample found a PSS score of $12.0 \pm 5.9$ in males and $13.7 \pm 6.6$ in females. ${ }^{14}$

Across specialties, our study has suggested that specialties frequently associated with high levels of stress were obstetrics/gynecology and radiology, followed by family Medicine. The long/unpredictable working hours and fear of patient complications among obstetrics/gynecology consultants and the large number of patients with wide range of complaints/management protocols seen by family physicians may explain these higher levels of stress. ${ }^{25,43}$ For radiologists, major sources of stress were suggested to be work overload, insufficiencies in staffing, facilities, and funding as well as impositions made on radiologists by other clinicians. ${ }^{44} \mathrm{How}-$ ever, this finding should be interpreted cautiously as it was derived from a limited number of radiologists (only $3.4 \%$ of the sample). Similar to the current finding, $43 \%$ of family physicians ${ }^{25}$ and $26 \%$ of gynecologic oncologists in Canada experienced high levels of stress. ${ }^{43} \mathrm{~A}$ local study compared three postgraduate residency training programs and found that the highest levels of stress were in emergency medicine, followed by internal and family medicine. ${ }^{41}$

In our study, we found female gender and the perception of a stressful working environment to be associated with higher perceived stress in a multivariate logistic regression analysis. Consistent with the current study, previous international studies have reported higher stress levels among female physicians compared with male physicians. ${ }^{17,45}$ Similarly, Saudi studies found a higher prevalence of stress among female residents,,${ }^{37}$ interns, ${ }^{40}$ and medical ${ }^{42}$ and dental ${ }^{39}$ students 
compared with their male counterparts. The gender-specific difference regarding stress has been attributed to the challenges of balancing family and career in a male-dominated profession and to the prejudice women experience from patients and colleagues alike. ${ }^{46}$ A nationwide survey of $>3,000$ Finnish physicians indicated that combining work and family was the most common reason for stress among females. $^{22}$ The female physicians had made compromises between family and work more frequently than their male counterparts (ie, restricted the number of children, postponed having children, given up postgraduate or continuing medical education, worked part-time because of family, and given up a job because of the spouse's need to move). ${ }^{22}$

Moreover, our study found that the perception of a stressful working environment was associated with a higher perception of stress. Similar findings were found among physicians in Saudi Arabia, ${ }^{47}$ the United Arab Emirates, ${ }^{17}$ Kuwait, ${ }^{48}$ Pakistan, ${ }^{29}$ Iran, ${ }^{19}$ and surgeons in the USA. ${ }^{49}$ Additionally, similar findings were observed among residents in Saudi Arabia. ${ }^{37}$ In our study, the vast majority of consultants considered their job environment to be stressful and almost half attributed that to having a high workload and a noncooperative administration. In the year preceding our survey, nearly half of the consultants frequently contemplated and even began action toward changing their hospitals/medical institutes or even moving to work outside of Saudi Arabia because of the perception of a stressful work environment. Another Saudi study among hospital staff showed that insufficient technical facilities, absences of appreciation, long working hours, short breaks, occurrences of health problems, changing hospitals, changing jobs, quitting practices, and undesired relationships with coworkers were found to correlate to job-related stress. ${ }^{47}$

Approximately $6 \%$ of consultants had frequent passive suicidal ideation, and $1 \%$ of them had frequent active suicidal ideation within the year prior to completing our survey. These suicidality figures are probably higher than the general Saudi Arabian population. ${ }^{50}$ A systematic review of 14 international studies found that the relative risk for suicide in physicians is between 1.1 and 3.4 for men and 2.5-5.7 for women compared with the general population and from 1.5 to 3.8 in males and from 3.7 to 4.5 in females compared with other professionals. ${ }^{51}$ It has been found that untreated mental illness is an important comorbidity for physicians who complete a suicide. ${ }^{52}$ Therefore, inadequate treatment and job-related stress are potentially modifiable risk factors that can reduce the rate of suicide among physicians. ${ }^{52}$
Unfortunately, most of the consultants in our study were neither educated nor trained in stress management. However, such education/training has not been associated with a lower stress level in the currently examined consultant population. This unexpected observation may be related to insufficient content or duration of such education or training or to the lack of organization-based interventions. A recent meta-analysis showed that while doctor-focused strategies are imperative, they are associated with small benefits unless boosted by implementation of organization-directed approaches, such as an improved work environment and an improved organizational culture. ${ }^{53}$

The current study used a national database to recruit a good number of consultants across several specialties and locations and used a well-validated tool to examine stress. Nevertheless, we acknowledge that there were some limitations. The cross-sectional study design precluded the finding of any causal association and self-reported data may lead to reporting bias. The convenience sampling and low response rate may negatively impact the generalizability of the current findings.

In conclusion, consultant physicians in Saudi Arabia experience moderate to high levels of perceived stress that are relatively comparable to the perceptions of stress reported by physicians worldwide. A significant association was found between stress level and both the female gender and the perception of a stressful work environment. We identified several institutional, professional, and personal stressors. Unfortunately, most of the consultants were neither educated nor trained in stress management. Further studies are required to assess physician-based interventions and organizationdirected approaches to manage stress among physicians.

\section{Acknowledgments}

The authors extend their appreciation to the deanship of scientific research, King Saud University for funding this work through the Student's Research Support Program, project no. USRSP-17-24. Furthermore, the authors would like to express their gratitude to Ashry Mohamed (Professor of Epidemiology and Family and Community Medicine), Abdulaziz Alzeer (Associate Professor of Medicine, Critical Care and Ethics), Mohammed Fouda (Professor of Cardiac Surgery), Mohammed Alzoghaibi (Associate Professor of Physiology), and Fatima Al Haider (Professor of Child and Adolescent Psychiatry) for their assistance in validation of the study questionnaire. Additionally, the authors thank Dr Aiman El-Saed (Assistant Professor of Epidemiology and Biostatistics) for his assistance in data analysis. The work 
was not supported or funded by any drug company. The data that support the findings of this study are available from the Saudi Commission for Health Specialties, but restrictions apply to the availability of these data, which were used under license for the current study, and so are not publicly available. Data are however available from the authors upon reasonable request and with permission of the Saudi Commission for Health Specialties.

\section{Disclosure}

The authors report no conflicts of interest in this work.

\section{References}

1. McCue JD. The effects of stress on physicians and their medical practice. N Engl J Med. 1982;306(8):458-463.

2. Schrijver I. Pathology in the medical profession? Taking the pulse of physician wellness and burnout. Arch Pathol Lab Med. 2016;140(9):976-982.

3. Shanafelt TD, Sloan JA, Habermann TM. The well-being of physicians. Am J Med. 2003;114(6):513-519.

4. Pedrazza M, Berlanda S, Trifiletti E, Bressan F. Exploring physicians' dissatisfaction and work-related stress: development of the PhyDis Scale. Front Psychol. 2016;7:1238.

5. Wallace JE, Lemaire JB, Ghali WA. Physician wellness: a missing quality indicator. Lancet. 2009;374(9702):1714-1721.

6. Landon BE, Aseltine R, Shaul JA, Miller Y, Auerbach BA, Cleary PD. Evolving dissatisfaction among primary care physicians. Am J Manag Care. 2002;8(10):890-901.

7. Kynes JM, Schildcrout JS, Hickson GB, et al. An analysis of risk factors for patient complaints about ambulatory anesthesiology care. Anesth Analg. 2013;116(6):1325-1332.

8. Schaad B, Bourquin C, Bornet F, et al. Dissatisfaction of hospital patients, their relatives, and friends: analysis of accounts collected in a complaints center. Patient Educ Couns. 2015;98(6):771-776.

9. Caplan RP. Stress, anxiety, and depression in hospital consultants, general practitioners, and senior health service managers. $B M J$. 1994;309(6964):1261-1263.

10. Al-Rowais NA. Assessment of stress and coping levels among physicians at King Khalid University Hospital. Saudi Med J. 1996;17(2):235-244.

11. Agha A, Mordy A, Anwar E, Saleh N, Rashid I, Saeed M. Burnout among middle-grade doctors of tertiary care hospital in Saudi Arabia. Work. 2015;51(4):839-847.

12. Saudi Commission for Health Specialties. Guidelines of Professional Classification and Registration For Health Practitioners, 2017. Available from: https://www.scfhs.org.sa/en/registration/Regulation/Documents/\%D8\%B1 \%D8\%AC\%D9\%85\%D8\%A9\%20\%D8\%A7\%D9\%84\%D9\%82\%D9\% 88\%D8\%A7\%D8\%B9\%D8\%AF3.pdf. Accessed December 29, 2017.

13. Cohen S, Kamarck T, Mermelstein R. A global measure of perceived stress. J Health Soc Behav. 1983;24(4):385-396.

14. Cohen S, Williamson G. Perceived stress in a probability sample of the United States. In: Spacapan S, Oskamp S, editors. The Social Psychology of Health. Newbury Park: SAGE; 1988:31-67.

15. Lee EH. Review of the psychometric evidence of the perceived stress scale. Asian Nurs Res (Korean Soc Nurs Sci). 2012;6(4):121-127.

16. Taylor JM. Psychometric analysis of the ten-item perceived stress scale. Psychol Assess. 2015;27(1):90-101.

17. Al Mazrouei AM, Al Faisal W, Hussein HY, El Sawaf EM, Wasfy AS Job related stress among physicians at Dubai Health Authority Hospitals - Dubai-UAE. Am J Psychol Cogn Sci. 2015;1(3):83-88.

18. Al Mazrouei AM, Al Faisal W, Hussein H, El Sawaf E, Wasfy A. Determinants of workplace stress among healthcare professionals in Dubai, physicians experience. Adv Appl Psychol. 2015;1(1):31-34.
19. Tavakoli Z, Montazeri A, Farshad AA, Lotfi Z, Noor Hassim I. Sources of stress and coping strategies among Iranian physicians. Glob J Health Sci. 2017;9(1):120.

20. Campolieti M, Hyatt D, Kralj B. Determinants of stress in medical practice evidence from Ontario physicians. Relations Ind. 2007;62(2):226-257.

21. Richardsen AM, Burke RJ. Occupational stress and job satisfaction among Canadian physicians. Work \& Stress. 1991;5(4):301-313.

22. Töyry S, Kalimo R, Äärimaa M, Juntunen J, Seuri M, Räsänen K. Children and work-related stress among physicians. Stress Health. 2004;20(4):213-221.

23. Simpson LA, Grant L. Sources and magnitude of job stress among physicians. J Behav Med. 1991;14(1):27-42.

24. Wolfgang AP. Job stress in the health professions: a study of physicians, nurses, and pharmacists. Hosp Top. 1988;66(4):24-27.

25. Lee FJ, Stewart M, Brown JB. Stress, burnout, and strategies for reducing them: what's the situation among Canadian family physicians? Can Fam Physician. 2008;54(2):234-235.

26. Gallery ME, Whitley TW, Klonis LK, Anzinger RK, Revicki DA. A study of occupational stress and depression among emergency physicians. Ann Emerg Med. 1992;21(1):58-64.

27. Heponiemi T, Aalto AM, Pekkarinen L, Siuvatti E, Elovainio M. Are there high-risk groups among physicians that are more vulnerable to on-call work? Am J Emerg Med. 2015;33(5):614-619.

28. Falkum E, Vaglum P. The relationship between interpersonal problems and occupational stress in physicians. Gen Hosp Psychiatry. 2005;27(4):285-291.

29. Aslam HD, Mansoor N, Suleman Q. Analysis of level of stress among doctors in public and private hospitals of Pakistan. Int J Learn Dev. 2013;3(2):109-135.

30. Atanes AC, Andreoni S, Hirayama MS, et al. Mindfulness, perceived stress, and subjective well-being: a correlational study in primary care health professionals. BMC Complement Altern Med. 2015;15(1):303.

31. Visser MR, Smets EM, Oort FJ, De Haes HC. Stress, satisfaction and burnout among Dutch medical specialists. CMAJ. 2003;168(3): 271-275.

32. Hutchinson TA, Haase S, French S, McFarlane TA. Stress, burnout and coping among emergency physicians at a major hospital in Kingston, Jamaica. West Indian Med J. 2014;63(3):262-266.

33. Wilkins K. Work stress among health care providers. Health Rep. 2007;18(4):33-36.

34. Swami MK, Mathur DM, Pushp BK. Emotional intelligence, perceived stress and burnout among resident doctors: an assessment of the relationship. Natl Med J India. 2013;26(4):210-213.

35. Atanes AC, Andreoni S, Hirayama MS, et al. Mindfulness, perceived stress, and subjective well-being: a correlational study in primary care health professionals. BMC Complement Altern Med. 2015;15(1):303.

36. Chaaya M, Osman H, Naassan G, Mahfoud Z. Validation of the Arabic version of the Cohen Perceived Stress Scale (PSS-10) among pregnant and postpartum women. BMC Psychiatry. 2010;10:111.

37. Alosaimi FD, Kazim SN, Almufleh AS, Aladwani BS, Alsubaie AS Prevalence of stress and its determinants among residents in Saudi Arabia. Saudi Med J. 2015;36(5):605-612.

38. El-Gilany AH, Amr M, Hammad S. Perceived stress among male medical students in Egypt and Saudi Arabia: effect of sociodemographic factors. Ann Saudi Med. 2008;28(6):442-448.

39. Al-Sowygh ZH. Academic distress, perceived stress and coping strategies among dental students in Saudi Arabia. Saudi Dent J. 2013;25(3):97-105.

40. Abdulghani HM, Irshad M, Al Zunitan MA, et al. Prevalence of stress in junior doctors during their internship training: a cross-sectional study of three Saudi medical colleges' hospitals. Neuropsychiatr Dis Treat. 2014;10:1879-1886.

41. Abdulghani HM, Al-Harbi MM, Irshad M. Stress and its association with working efficiency of junior doctors during three postgraduate residency training programs. Neuropsychiatr Dis Treat. 2015;11:3023-3029. 
42. Abdulghani HM, AlKanhal AA, Mahmoud ES, Ponnamperuma GG, Alfaris EA. Stress and its effects on medical students: a cross-sectional study at a college of medicine in Saudi Arabia. J Health Popul Nutr. 2011;29(5):516-522.

43. Elit L, Trim K, Mand-Bains IH, Sussman J, Grunfeld E; Society of Gynecologic Oncology Canada. Job satisfaction, stress, and burnout among Canadian gynecologic oncologists. Gynecol Oncol. 2004;94(1):134-139.

44. Graham J, Ramirez AJ, Field S, Richards MA. Job stress and satisfaction among clinical radiologists. Clin Radiol. 2000;55(3):182-185.

45. Adam S. Work-Family Conflict Among Female and Male Physicians in Hungary: Prevalence, Stressor Predictors and Potential Consequences on Physicians' Well-Being [doctoral thesis]. Budapest: Semmelweis University; 2008.

46. Levey RE. Sources of stress for residents and recommendations for programs to assist them. Aecad Med. 2001;76(2):142-150.

47. Al-Omar B. Sources of work-stress among hospital-staff at the Saudi. JKAU Econ Adm. 2003;17(1):3-16.
48. Shah MA, Al-Enezi N, Chowdhury RI, Shah NM. Correlates of job satisfaction among health care professionals in Kuwait. Med Princ Pract. 2001;10(3):156-162.

49. Campbell DA, Sonnad SS, Eckhauser FE, Campbell KK, Greenfield LJ. Burnout among American surgeons. Surgery. 2001;130(4): 696-705.

50. World Health Organisation. Mental Health: WHO Suicide data. WHO. Available from: http://www.who.int/mental_health/prevention/suicide/ suicideprevent/en/. Accessed November 20, 2017.

51. Lindeman S, Laara E, Hakko H, Lonnqvist J. A systematic review on gender-specific suicide mortality in medical doctors. Br J Psychiatry. 1996;168(3):274-279.

52. Gold KJ, Sen A, Schwenk TL. Details on suicide among US physicians: data from the National Violent Death Reporting System. Gen Hosp Psychiatry. 2013;35(1):45-49.

53. Panagioti M, Panagopoulou E, Bower P, et al. Controlled interventions to reduce burnout in physicians: a systematic review and meta-analysis. JAMA Intern Med. 2017;177(2):195-205.

\section{Publish your work in this journal}

Advances in Medical Education and Practice is an international, peerreviewed, open access journal that aims to present and publish research on Medical Education covering medical, dental, nursing and allied health care professional education. The journal covers undergraduate education, postgraduate training and continuing medical education including emerging trends and innovative models linking education, research, and health care services. The manuscript management system is completely online and includes a very quick and fair peer-review system. Visit http://www.dovepress.com/testimonials.php to read rea quotes from published authors.

Submit your manuscript here: http://www.dovepress.com/advances-in-medical-education-and-practice-journal 